\title{
Media Pop-Up Book Berorientasi Pendekatan Saintifik pada Muatan Pelajaran PPKn Kelas V Sekolah Dasar
}

\section{Ni Komang Putriningsih ${ }^{*}$, Made Putra²}

1,2 Program Studi Pendidikan Guru Sekolah Dasar, Universitas Pendidikan Ganesha, Singaraja, Indonesia

\section{ART I CLE IN F O}

Received 22 Februari 2021

Revised 23 April 2021

Accepted 14 Mei 2021

Available online 25 Juni 2021

Kata Kunci:

Pop-up Book, scientific, PPKn

Keywords:

Pop-up Book, scientific, PPKn
Article history:

\begin{abstract}
A B S T R A K
Kurangnya ketersediaan media di sekolah dan metode pembelajaran yang digunakan guru masih dominan menggunakan metode ceramah sehingga berdampak pada hasil belajar siswa yang rendah. Penelitian ini bertujuan mengembangkan media Pop-up Book dan mengetahui validitas media tersebut. Penelitian in merupakan penelitian pengembangan (R\&D) dengan model pengembangan ADDIE (Analyze, Design, Development, Implementation, Evaluation). Subjek pada penelitian ini yaitu ahli isi muatan pelajaran, ahli desain pembelajaran, ahli media pembelajaran, dan siswa kelas V SD. Metode pengumpulan data menggunakan kuesioner. Instrumen yang digunakan dalam mengumpulkan data yaitu kuesioner. Data yang diolah menggunakan
\end{abstract} teknik analisis deskriptif kuantitatif. Hasil penelitian ini menunjukkan bahwa dari aspek isi pembelajaran, media ini berkualifikasi sangat baik dengan persentase $93,75 \%$, dari aspek desain pembelajaran media ini berkualifikasi sangat baik dengan persentase $97,22 \%$, dari aspek media pembelajaran, media ini berkualifikasi sangat baik dengan persentase $93,18 \%$, dan dari uji coba perorangan, media ini berkualifikasi sangat baik dengan persentase $98,3 \%$. Jadi media Pop-up Book yang berorientasi pendekatan saintifik ini layak digunakan pada muatan pelajaran PPKn kelas V SD. Implikasi dari penelitian ini yaitu secara empiris terbukti bahwa penggunaan media Pop-up Book dapat menarik perhatian siswa dan memotivasi siswa untuk belajar.

\section{A B S T R A C T}

The lack of media availability in schools and the learning methods used by teachers are still dominantly using the lecture method so that it has an impact on low student learning outcomes. This study aims to develop Pop-up Book media and determine the validity of the media. This research is a development research (R\&D) with the ADDIE development model (Analyze, Design, Development, Implementation, Evaluation). The subjects in this study were content experts, learning design experts, learning media experts, and fifth grade elementary school students. Methods of data collection using a questionnaire. The instrument used in collecting data is a questionnaire. The data were processed using quantitative descriptive analysis techniques. The results of this study indicate that from the aspect of learning content, this media is very well qualified with a percentage of $93.75 \%$, from the aspect of learning design this media is very well qualified with a percentage of $97.22 \%$, from the aspect of learning media, this media is very well qualified with a percentage $93.18 \%$, and from individual trials, this media is very well qualified with a percentage of $98.3 \%$. So this scientific approach-oriented Pop-up Book media is suitable for use in the content of Civics lessons for fifth grade elementary school. The implication of this research is that it is empirically proven that the use of Pop-up Book media can attract students' attention and motivate students to learn.

\section{Pendahuluan}

Salah satu muatan pembelajaran yang diintegrasikan dalam pembeljran tematik adalah Pendidikan Kewarganegaraan (PPKn). PPKn adalah satu bidang ilmu ilmu yang mencari jawaban atas pertanyaan apa, mengapa, dan bagaimana gejala-gejala sosial, khususnya yang berkaitan dengan moral serta perilaku manusia yang didasarkan oleh adanya anomali moral dalam perilaku-perilaku sosial di

Copyright (C) Universitas Pendidikan Ganesha. All rights reserved 
sekitar lingkungan masyarakat kita (Dewi, Asri, \& Suniasih, 2019; Sriyanto, Leksono, \& Harwanto., 2019). PPKn merupakan salah satu muatan pelajaran yang mengajarkan siswa untuk berperilaku yang baik di masyarakat. Secara nyata, mata pelajaran Pendidikan Kewarganegaraan bertujuan agar peserta didik mampu menanggapi isu kewarganegaraan secara kritis, rasional, dan kreatif. Disamping itu, PPKn juga bertujuan menjadikan peserta didik berkembang secara positif dan demokratis berdasarkan karakterkarakter masyarakat Indonesia (Kurniaman \& Wuryandani, 2017; Solehana, Asrori, \& Usman, 2019).

Berdasarkan realita dilapangan, saat ini PPKn nampaknya menjadi pembelajaran yang kurang diminati oleh peserta didik karena karakteristik materi pembelajarannya yang bersifat hafalan sehingga dianggap rumit dan membosankan untuk dipelajari (Kurniawan \& Wuryandani, 2017; Suprihatin, 2017). Pembelajaran PPKn sering dipandang sebagai pembelajaran yang membosankan karena kurangnya kemampuan guru dalam memberikan variasi pembelajaran sehingga sangat dibutuhkan media mengajar yang menarik siswa untuk belajar (Kurniawan \& Saragih, 2016; Sriyanto et al., 2019). Selain itu, untuk memecahkan permasalahan pembelajaran PPKn yang kurang optimal, guru dituntut untuk memiliki kemampuan dalam memvariasikan sajian pembelajaran (Indrianto \& Kurniawati, 2020). Dari hasil wawancara lebih lanjut guru menyampaikan bahwa keterbatasan waktu yang dimiliki guru menyebabkan terhambatnya perancangan dan pengembangan media. Ditambah lagi dengan kondisi Covid-19 yang terjadi saat ini, mengakibatkan siswa kurang maksimal dalam belajar. Pembelajaran yang dilakukan secara daring lebih dominan menggunakan teknik penugasan. Dari observasi yang dilakukan, ditemukan bahwa media yang tersedia masih sangat terbatas. Keterbatasan media ini menyebabkan jarangnya penggunaan media dalam proses pembelajaran. Guru sendiri semestinya bertugas sebagai fasilitator sekaligus mediator yang dituntut mampu mengkondisikan siswa dalam belajar (Darmadi, 2015; Karisma, Margunayasa, \& Prasasti, 2020; Palunga \& Marzuki, 2017). Dalam hal ini, keberadaan media pembelajaran pada proses pembelajaran dipandang sangat perlu karena dengan didampingi media maka pembelajaran akan terasa menjadi lebih berkesan dan tidak monoton (Sentarik \& Kusmariyatni, 2020).

Salah satu opsi yang bisa digunakan untuk memfasilitasi siswa dan membuat pembelajaran lebih variatif pada pembelajaran PPKn adalah melalui pemanfaatan media pembelelajaran (Putri, 2019). Media pembelajaran sendiri adalah salah satu cara yang dapat digunakan guru untuk meningkatkan kualitas pembelajaran (Arianti, Wiarta, \& Darsana, 2019; Kurnia, Damayani, \& Kiswoyo, 2019). Media pembelajaran memiliki pengaruh besar terhadap minat belajar siswa yang akan berimbas pada hasil belajarnya (Lestari, Putra, \& Negara, 2018; Mediatati \& Suryaningsih, 2017). Salah satu media pembelajaran yang dapat digunakan yaitu Pop-up Book. Pop-up Book merupakan salah satu media pembelajaran kreatif yang bisa menarik perhatian siswa untuk belajar. Pop-up Book merupakan salah satu inovasi dalam media pembelajaran dengan menampilkan isi dari sebuah buku dalam bentuk 3 dimensi yang ditampilkan melalui penggabungan gulungan, putaran, maupun lipatan (Baiduri, Marhan, \& Lufita, 2019; Mustofa \& Syafi'ah, 2018). Pop-up Book merupakan buku yang terdiri dari halaman-halaman yang dapat bergerak ketika halaman dibuka dan di dalam halaman-halaman tersebut terdapat gambar-gambar yang memiliki unsur tiga dimensi yang ditujukan agar pembaca tidak jenuh saat membaca (Diyantari, Wiyasa, \& Manuaba, 2020; Mustika \& Ain, 2020). Gambar yang ada pada media Pop-up Book dapat bergerak sesuai rancangannya. Perancangan Pop-up Book dapat dilakukan dengan menyesuaikan kebutuhan materi, karakteristik siswa dan memperhatikan langkah-langkah pembelajaran yang akan dilakukan untuk siswa. Pendekatan yang digunakan pada media pembelajaran ini yaitu pendekatan saintifik. Pendekatan saintifik menggunakan keterampilan 5M yang terdiri dari mengamati, menanya, mengumpulkan, mengasosiasi, dan mengkomunikasikan (Salim, 2016; Sophuan, 2018). Pendekatan saintifik akan memberikan stimulus bagi otak peserta didik untuk terbiasa dalam berpikir sehingga akan berdampak pada perkembangan otak peserta didik (Maulidati, et al., 2019). Pendekatan saintifik dirancang agar siswa secara aktif dapat menemukan sebuah konsep, merumuskan konsep, mengumpulkan data dari konsep dan menarik kesimpulan, dan mengomunikasikan konsep yang ditemukan (Katimo, Suparmi, \& Sukarmin, 2016; Qondias, Winarta, \& Siswanto, 2019).

Temuan penelitian sebelumnya menyatakan bahwa media pembelajaran dapat membantu siswa yang kesulitan dalam belajar (Dewi, Kristiantari, \& Ganing, 2019; Hanifah \& Budiman, 2019; Wulandari, Sudatha, \& Simamora, 2020). Temuan penelitian lainnya juga menyatakan bahwa media Pop-up Book dapat meningkatkan motivasi dan semangat belajar siswa (Abhyasari, Kusmariyatni, \& Agustiana, 2020; E D Masturah, Mahadewi, \& Simamora, 2018; Ningtiyas, Setyosari, \& Praherdiono, 2019). Belum adanya kajian mengenai media pop-up book berorientasi pendekatan saintifik pada muatan pelajarna PPKn kelas V sekolah dasar. Berdasarkan hal ini, maka dilakukan penelitian pengembangan media Pop-up Book untuk membantu meningkatkan kemampuan berpikir siswa. Kelebihan dari media yang dikemabangkan ini yaitu mampu merangsang imajinasi siswa, sehingga siswa dilatih dalam mengemukakan ide-ide dalam pembelajaran. Selain itu dengan kegiatan membuka, melipat, dan menggeser bagian pop-up book dapat menjadi pengalaman khusus bagi siswa. Kegiatan ini akan memberikan kesan bagi siswa sehingga materi 
akan mudah masuk kedalam ingatan ketika menggunakannya. Penelitian ini dilakukan dengan tujuan untuk mengembangkan media Pop-up Book berorientasi pendekatan saintifik pada muatan pelajaran PPKn kelas V SD. Diharapkan media pembelajaran ini dapat membantu siswa dalam belajar sehingga berdampak pada peningkatan hasil belajar PPKn pada siswa.

\section{Metode}

Model Jenis penelitian ini adalah penelitian pengembangan (Research and Development/ R\&D). Penelitian dan pengembangan (Research and Development/ $R \& D$ ) merupakan metode penelitian yang ditujukan untuk menghasilkan sebuah produk baru dan melakukan pengujian terhadap produk tersebut (Sugiyono, 2019). Model pengembangan yang digunakan dalam penelitian ini adalah model $A D D I E$ yang terdiri dari lima tahapan yaitu: (1) Analisis (analyze), (2) Desain (design), (3) Pengembangan (development), (4) Implementasi (implementation), (5) Evaluasi (evaluation).

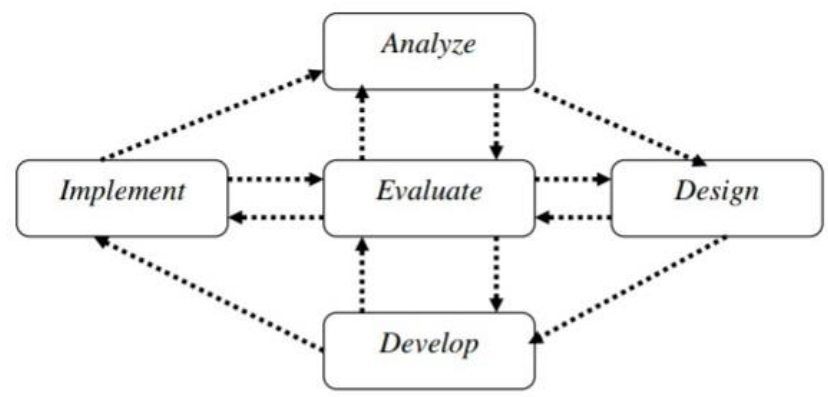

Gambar 1. Langkah-Langkah Model Pengembangan ADDIE (Tegeh, et al., 2014)

Penelitian ini dilakukan di SD No. 4 Sibangkaja yang terletak di Banjar Lambing, Desa Sibangkaja, Kecamatan Abiansemal, Kabupaten Badung, Provinsi Bali. Subjek dalam penelitian ini diantaranya 1) ahli isi muatan pelajaran, 2) ahli desain pembelajaran, 3) ahli media pembelajaran, dan 4) siswa kelas V di SD. Ahli isi muatan pelajaran merupakan seorang dosen yang mengajar di Jurusan Pendidikan Dasar di Universitas Pendidikan Ganesha. Ahli desain dan media pembelajaran merupakan seorang dosen yang mengajar di Jurusan Teknologi Pendidikan Universitas Pendidikan Ganesha. Subjek uji coba atau pengguna produk adalah 3 orang siswa kelas V SD No. 4 Sibangkaja yang terdiri dari siswa berkemampuan tinggi, sedang, dan rendah Metode pengumpulan data pada penelitian ini menggunakan kuesioner. Instrumen yang digunakan untuk mengumpulkan data juga berupa kuesioner. Kuesioner digunakan untuk mengumpulkan data dari evaluasi ahli isi muatan pelajaran, ahli desain pembelajaran, ahli media pembelajaran, dan siswa kelas V SD. Adapun kisi-kisi instrumen yang digunakan dalam penelitian dapat dilihat pada table 1, 2, 3, dan 4.

Tabel 1. Kisi-Kisi Instrumen Validasi Isi Muatan Pelajaran

\begin{tabular}{ccll}
\hline No. & Aspek & & \multicolumn{1}{c}{ Indikator } \\
\hline 1. & Kurikulum & a. & Kesesuaian materi dengan kompetensi dasar \\
& & b. & Kesesuaian materi dengan indikator \\
& & c. & Kesesuaian materi dengan tujuan pembelajaran \\
2. & Materi & a. & Kecakupan materi \\
& & b. & Kedalaman materi \\
& & c. & Materi mempresentasika kehidupan nyata \\
& & d. & Materi mudah dipahami \\
3. & Evaluasi & a. & Kesesuaian soal dengan materi \\
\hline
\end{tabular}

Tabel 2. Kisi-Kisi Instrumen Validasi Desain Pembelajaran

\begin{tabular}{clll}
\hline No. & \multicolumn{1}{c}{ Aspek } & & \multicolumn{1}{c}{ Indikator } \\
\hline 1. & Kurikulum & a. & Kejelasan tujuan pembelajaran \\
2. & Strategi & a. & Ketepatan strategi yang digunakan \\
& & b. & Kesesuaian strategi \\
& & c. & Kejelasan kegiatan pembelajaran \\
3. & Pembelajaran & a. & Materinya bermanfaat dalam kehidupan nyata \\
& & b. & Penyajian materi mampu memotivasi siswa \\
\hline
\end{tabular}




\begin{tabular}{cccl}
\hline No. & Aspek & & \multicolumn{1}{c}{ Indikator } \\
\hline & \multirow{3}{*}{ Evaluasi } & c. & Penyajian materi menarik perhatian siswa \\
& & a. & Kejelasan petunjuk pengerjaan soal \\
& b. & Kesesuaian soal dengan materi \\
\hline
\end{tabular}

Tabel 3. Kisi-Kisi Instrumen Validasi Media Pembelajaran

\begin{tabular}{ccll}
\hline No. & Aspek & & \multicolumn{1}{c}{ Indikator } \\
\hline 1. & Tampilan & a. & Keterbacaan teks \\
& & b. & Ketepatan penggunaan jenis huruf, ukuran huruf, dan spasi \\
& & c. & Penggunaan gambar yang mendukung isi materi \\
& & d. & Ketepatan komposisi dan kombinasi warna \\
2. Strategi & a. Kejelasan Petunjuk penggunaan media \\
& & b. Kemudahan penggunaan media \\
& & c. Penggunaan media dapat membantu siswa dalam pemahaman materi \\
3. & Evaluasi & d. & a. \\
& &
\end{tabular}

Tabel 4. Kisi-Kisi Instrumen Uji Coba Perorangan

\begin{tabular}{|c|c|c|}
\hline No. & Aspek & Indikator \\
\hline \multirow[t]{3}{*}{1.} & Tampilan & a. $\quad$ Keterbacaan teks \\
\hline & & b. Penggunaan gambar mendukung isi materi \\
\hline & & c. Ketepatan kombinasi warna \\
\hline \multirow[t]{4}{*}{2.} & Materi & a. Kecakupan materi \\
\hline & & b. Materi mempersentasikan kehidupan nyata \\
\hline & & c. Materi didukungdengan media yang tepat \\
\hline & & d. Kecakupan materi \\
\hline \multirow[t]{3}{*}{3.} & Pengoprasian & a. Kemudahan penggunaan media \\
\hline & & b. Media dapat membantu siswa dalam pemahaman materi \\
\hline & & c. Media dapat dikontrol siswa sesuai dengan kecepatan berpikirnya \\
\hline 4 & Evaluasi & a. Penyajian soal untuk pemahaman materi \\
\hline
\end{tabular}

Data yang dianalisis dalam penelitian ini menggunakan teknik analisis kualitatif dan kuantitatif. Analisis kulitatif digunakan untuk menganalisis hasil pengumpulan data dari tinjauan ahli menggunakan pendekatan kuantitatif. Miles dan Hubermen (dalam Dewanti et al., 2018) mengemukakan bahwa aktivitas dalam analisis data kualitatif dilakukan secara interaktif sehingga data hasil pemberian skor, masukan, tanggapan, kritik, dan saran perbaikan akan dianalisis secara deskriptif kemudian digunakan sebagai pertimbangan revisi produk. Data kuantitatif dianalisis menggunakan teknik analisis deskriptif dengan presentase. Teknik ini digunakan untuk menganalisis data yang diperoleh dari hasil uji coba terbatas pada siswa kelas V.

\section{Hasil dan Pembahasan}

Penyajian data hasil uji coba pada penelitian ini dibagi menjadi dua uraian yaitu rancang bangun media Pop-up Book dan validitas media Pop-up Book. Pengembangan media yang dilakukan pada penelitian ini menggunakan model pengembangan ADDIE yang meliputi tahapan analisis (analyze), tahap desain (design), tahap pengembangan (development), tahap implementasi (implementation), dan tahap evaluasi (evaluation). Tahap pertama yaitu analisis (analyze). Kegiatan analisis yang dilakukan meliputi tiga kegiatan yaitu: (a) analisis karakteristik siswa, (b) analisis konten dan fasilitas, dan (c) analisis kompetensi siswa. Kegiatan analisis pertama adalah analisis karakteristik siswa. Kegiatan analisis karakteristik siswa dilakukan untuk mengetahui karakter siswa pada proses pembelajaran. Dari hasil wawancara bersama guru wali kelas V didapatkan informasi bahwa siswa tergolong aktif jika belajar dengan media visual dan dari hasil respon angket analisis karakteritik siswa melalui Google form diketahui bahwa siswa cenderung lebih suka belajar dari hasil wawancara bersama guru wali kelas $\mathrm{V}$ didapatkan informasi bahwa siswa kelas V SD No. 4 Sibangkaja tergolong aktif jika belajar dengan media visual dan dari hasil respon angket analisis karakteritik siswa melalui Google form diketahui bahawa siswa cenderung lebih suka belajar. (b) kegiatan analisis kedua yaitu analisis konten dan fasilitas. Kegiatan analisis konten dan fasilitas dilakukan melalui pemilihan materi yang relevan dengan produk yang akan dikembangkan peneliti. analisis fasilitas dilakukan dengan melakukan observasi dan 
wawancara mengenai fasilitas yang dimiliki sekolah maupun lingkungan belajar siswa. Melalui analisis ini ditentukan bahwa media yang dikembangkan yaitu Pop-up Book dengan pembatasan materi yaitu muatan pelajaran PPKn kelas V, dengan pembatasan isi materi yaitu hak, kewajiban, dan tanggung jawab warga masyarakat. (c) kegiatan analisis ketiga adalah analisis kompetensi siswa. Kegiatan analisis kompetensi siswa tentunya dilakukan untuk mengetahui kompetensi yang digunakan dalam proses pembelajaran dan kompetensi muatan pelajaran PPKn yang digunakan mengacu pada Kurikulum 2013. Tahap kedua yaitu desain (design). Kegiatan yang dilakukan pada tahap desain ini meliputi pembuatan flowchart dan storyboard yang digunakan pedoman untuk melakukan pembuatan produk pada tahap pengembangan. Kemudian pada tahapan ini juga dilakukan pemilihan software yang digunakan untuk mengembangkan produk. Adapun software yang digunakan untuk mengembangkan produk media Pop-up Book yaitu aplikasi Canva, Photoshop, dan Corel Draw.

Tahap ketiga yaitu pengembangan (development). Kegiatan yang dilakukan pada tahap pengembangan ini meliputi penerjemahan desain ke dalam bentuk fisik dan pemilihan unsur visual. Pemilihan unsur visual yang dimaksud yaitu seperti pemilihan gambar yang relevan dengan materi, kombinasi warna yang digunakan, dan penentuan bentuk fisik produk media Pop-up Book. Tahap keempat yaitu implementasi (implementation). Tahap implementasi merupakan tahap uji coba produk oleh pengguna (siswa). Uji coba produk yang dilakukan kepada siswa hanya sampai pada uji coba perorangan. Sebelum produk digunakan oleh siswa, tentunya produk harus divalidasi atau review oleh para ahli yang meliputi ahli isi materi, ahli desain pembelajaran, dan ahli media pembelajaran. Tujuan dilakukanya validasi tersebut yaitu untuk menentukan kelayakan produk yang dikembangkan. Adapun hasil akhir dari pengembangan media Pop-up Book yang berorientasi pendekatan saintifik pada muatan pelajaran PPKn dapat dilihat pada gambar sebagai berikut.


Gambar 2. Media Pop-up Book yang dikembangkan

Hasil uji validitas media Pop-up Book ditinjau dari empat subjek yang terdiri dari: 1) uji ahli isi muatan pelajaran, 2) uji ahli desain pembelajaran, 3) uji ahli media pembelajaran, dan 4) uji coba perorangan pada siswa kelas V SD. Hasil validitas pengembangan media Pop-up Book secara lebih rinci dapat dilihat pada tabel sebagai berikut.

Tabel 5. Persentase Hasil Validitas Media Pop-up Book

\begin{tabular}{llcl}
\hline No & Subjek Uji Coba & Hasil Validitas (\%) & $\begin{array}{c}\text { Kualifikasi } \\
\text { Persentase }\end{array}$ \\
\hline 1. & Uji ahli isi muatan pelajaran & 93,75 & Sangat Baik \\
2. & Uji ahli desain pembelajaran & 97,22 & Sangat Baik \\
3. & Uji ahli media pembelajaran & 93,18 & Sangat Baik \\
4. & Uji coba perorangan & 98,33 & Sangat Baik \\
\hline
\end{tabular}

Dari tabel 5 di atas diketahui bahwa hasil validitas media Pop-up Book memperoleh hasil $>90 \%$ dengan kualifiksi sangat baik. Namun hal tersebut tidak menutup kemungkinan untuk diadakannya revisi lebih lanjut. Berikut merupakan komentar, masukan dan saran dari keempat subjek uji coba di atas. Adapun saran yang diberikan oleh ahli yaitu cukup menarik tinggal dikuatkan gambar pada media ini agar bisa tegak dengan kokoh ketika dibuka. Berdasarkan hasil penelitian yang telah dipaparkan diatas, terungkap bahwa media pop-up book layak digunakan dalam pembelajaran. Terdapat beberapa hal yang dapat dicermati untuk menentukan apakah media pembelajaran layak digunakan dalam pembelajaran. 
Adapun hal tersebut dipaparkan sebagai berikut. Pertama, media pop-up book layak digunakan dalam pembelajaran karena kemasan materi yang menarik. Implikasi dari materi yang dikemas secara menarik berdampak pada peningkatan daya tarik belajar siswa. Pemilihan media memang harus disesuaikan dengan materi pelajaran, karena masing-masing muatan pelajaran memiliki karakteristik yang berbeda (Oktarina \& Liyanovitasari, 2019; Suwatra, Magta, \& Christiani, 2019; Vista, Hermita, \& Zufriady, 2019). Pemilihan media dan muatan materi yang tepat guna akan menghasilkan pembelajaran yang interaktif, sehingga materi pembelajaran dapat disampaikan dengan baik (Mustofa \& Syafi'ah, 2018; Yendrita \& Syafitri, 2019). Isi materi pelajaran akan dapat tersampaikan dengan baik jika damping dengan penggunaan media yang sesuai dengan situasi dan kondisi (Primasari, 2014; Yuanta, 2019). Kekhasan aktivitas atau proses pengoperasian media Pop-up Book sebagai salah satu bntuk media pembelajaran cetak. Aktivitas yang dilakukan pada media ini dapat menarik perhatian siswa untuk memfokuskan konsentrasinya. Media Pop-up Book merupakan media yang memiliki unsur 3 dimensi dan memiliki visualisasi yang menarik(Fitri \& Karlimah, 2018; Sari \& Azzah, 2017). Dalam pengimlementasiannya guru dirancang memberikan atau membacakan sedikit materi tentang hak, kewajiban, dan tanggung jawab warga masyarakat sedangkan siswa akan menyimak dan mengamati gambar. Kemudian siswa akan diminta untuk mendemontrasikan media tersebut dengan menjelaskan makna dari gambar yang ada di pop-up book dan memberikan ide-ide terkait pemecahan masalah yang sudah disediakan di dalam pop-up book (Elisa Diah Masturah, Mahadewi, \& Simamora, 2018; Nikmah, Nuroso, \& Reffiane, 2019). Hal ini akan membuat siswa fokus dan konsentrasi dalam mengikuti pembelajaran.

Kedua, media pop-up book layak digunakan dalam pembelajaran karena pemilihan strategi belajar yang tepat. Pemilihan strategi pembelajaran yang tepat juga berdampak baik pada proses pembelajaran.Peninjauan desain dan strategi pembelajaran didasarkan dari rencana pelaksanaan pembelajaran (RPP) yang digunakan. Strategi pembelajaran yang digunakan dalam media pop-up book ini adalah strategi pendekatan saintifik dengan pertimbangan bahwa pendekatan saintifik akan mampu meningkatkan fokus belajar dan motivasi siswa sehingga akan berpengaruh terhadap hasil belajar siswa (Ardaya, 2016; Marwiyati \& Istiningsih, 2021). Pendekatan saintifik adalah suatu proses pembelajaran yang dirancang supaya peserta didik secara aktif mengkonstruk konsep, hukum, atau prinsip melalui kegiatan mengamati, merumuskan masalah, mengajukan/merumuskan hipotesis, mengumpulkan data dengan berbagai teknik, menganalisis data, menarik kesimpulan, dan mengkomunikasikan (Meilani, Dantes, \& Tika, 2020; Widnyani, Dantes, \& Tegeh, 2015). Dalam hal ini pendekatan saintifik pada media pop-up book sangat penting untuk melatih peserta didik dalam mengkomunikasikan ide-ide dan meningkatkan kemampuan siswa dalam menyelesaikan masalah secara sitematik khususnya dilingkungan masyarakat, seperti hak, kewajiban dan tanggung jawab siswa sebagai warga masyarakat.

Temuan penelitian sebelumnya juga menyatakan media pop-up book dapat memudahkan siswa dalam belajar dan menciptakan pembelajaran menjadi menyenangkan (Baiduri et al., 2019; Rusmiati \& Nugroho, 2019). Temuan penelitian lainnya juga menyatakan bahwa media pop-up book dapat meningkatkan hasil belajar siswa (Handaruni Dewanti, Anselmus J E Toenlioe, 2018; Karisma et al., 2020). Sehingga dapat disimpulkan bahwa media pop-up book dapat memudahkan siswa dalam belajar serta meningkatkan semangat siswa dalam belajar. Implikasi penelitian ini yaitu media yang dikembangkan dapat meningkatkan motivasi belajar siswa sehingga berdampak pada hasil belajar siswa yang meningkat.

\section{Simpulan}

Media Pop-up Book berorientasi pendekatan saintifik pada muatan pelajaran IPA kelas V SD mendapatkan kategori sangat baik. Media Pop-up Book yang berorientasi pendekatan saintifik ini layak digunakan pada muatan pelajaran IPA kelas V SD dapat diterapkan dalam proses pembelajaran. Direkomendasikan kepada para guru untuk menggunakan media Pop-up Book yang dapat meningkatkan semangat dan memudahkan siswa dalam memahami materi pembelajaran.

\section{Daftar Rujukan}

Abhyasari, N. P., Kusmariyatni, N. N., \& Agustiana, I. G. A. T. (2020). Pengaruh Pembelajaran Berpendekatan Saintifik Berbasis Masalah Terhadap Disiplin dan Hasil Belajar IPA. Mimbar PGSD Undiksha, 8(1), 111-122. https://doi.org/http://dx.doi.org/10.23887/jjpgsd.v8i1.24547.

Ardaya, D. A. (2016). Penerapan Pendekatan Saintifik Untuk Kelas V Sekolah Dasar. Jurnal Pendidikan Guru Sekolah Dasar, I(I), 72-83. https://doi.org/https: //doi.org/10.17509/jpgsd.v4i1.20527.

Arianti, Wiarta, \& Darsana. (2019). Pengaruh Model Pembelajaran Problem Posing Berbantuan Media Semi Konkret terhadap Kompetensi Pengetahuan Matematika. Jurnal Ilmiah Sekolah Dasar, 3(4). https://doi.org/https://doi.org/10.23887/jisd.v3i4.21765. 
Baiduri, Marhan, \& Lufita. (2019). Pengembangan media pembelajaran pop-up book berbasis audio pada materi bangun datar segiempat. Jurnal Program Studi Pendidikan Matematika, 8(1). https://doi.org/http://dx.doi.org/10.24127/ajpm.v8i1.1951.

Darmadi. (2015). Peran, Kompetensi, Dan Tanggung Jawab Menjadi Guru Profesional. Jurnal Pendidikan, 13(1), 161-174. https://doi.org/http://dx.doi.org/10.31571/edukasi.v13i2.113.

Dewi, Asri, \& Suniasih. (2019). Pengaruh Model Quantum Teaching Berbasis Tri Hita Karana Terhadap Kompetensi Pengetahuan Ppkn Siswa Kelas V. Jurnal Pendidikan Multikultural Indonesia, 2(1), 3334. https://doi.org/http://dx.doi.org/10.23887/jpmu.v2i1.20790.

Dewi, N. N. K., Kristiantari, M. . R., \& Ganing, N. N. (2019). Pengaruh Model Pembelajaran Picture And Picture Berbantuan Media Visual Terhadap Keterampilan Menulis Bahasa Indonesia. Journal of Education Technology, 3(4). https://doi.org/http://dx.doi.org/10.23887/jet.v3i4.22364.

Diyantari, I. A. K. D., Wiyasa, N., \& Manuaba, S. (2020). Model Snowball Throwing Berbantuan Media Pop Up Book Berpengaruh Terhadap Kompetensi Pengetahuan Ipa. Jurnal Ilmiah Pendidikan Profesi Guru, 3(1), 9-21. https://doi.org/http://dx.doi.org/10.23887/jippg.v3i1.26973.

Fitri, N. A., \& Karlimah. (2018). Pengembangan Media Pop-Up Book Kubus dan Balok untuk Siswa Kelas V Sekolah Dasar. PEDADIDAKTIKA: Jurnal Ilmiah Pendidikan Guru Sekolah Dasar, 5(4), 226-239.

Handaruni Dewanti, Anselmus J E Toenlioe, Y. S. (2018). Pengembangan media Pop-Up Book untuk Pembelajaran Lingkungan Tempat Tinggalku Kelas IV SDN 1 Pakuaden Kabupaten Ponorogo. Jurnal Kajian Teknologi Pendidikan, 1(3), 221-228. Retrieved from http://journal2.um.ac.id/index.php/jktp/article/view/4551.

Hanifah, \& Budiman. (2019). Pengaruh Model Open Ended Problem Berbantu Media Kotak Telur Pelangi ( Kotela ) Terhadap Hasil Belajar. Journal of Education Technology., 3(3), 1-137. https://doi.org/http://dx.doi.org/10.23887/jet.v3i3.21734.

Indrianto, N., \& Kurniawati. (2020). Developing Pop-Up Book Based Media To Improve The First Grader Students' Learning Achievement on The Theme of Natural Event of Min 4 Jember. Jurnal Pendidikan Dasar Nusantara, 5(2), 279-291. https://doi.org/10.29407/jpdn.v5i2.13836.

Karisma, I. K. E., Margunayasa, I. G., \& Prasasti, P. A. T. (2020). Pengembangan Media Pop-Up Book pada Topik Perkembangbiakan Tumbuhan dan Hewan Kelas VI Sekolah Dasar. Jurnal Ilmiah Sekolah Dasar, 4(2), 121. https://doi.org/10.23887/jisd.v4i2.24458.

Katimo, Suparmi, \& Sukarmin. (2016). Pengaruh Pembelajaran dengan Pendekatan Saintifik Menggunakan Metode Eksperimen dan Demonstrasi terhadap Prestasi dan Kreativitas Ditinjau dari Sikap Ilmiah. Inkuiri: Jurnal Pendidikan https://doi.org/https://doi.org/10.20961/inkuiri.v5i2.9482.

Kurnia, V. T., Damayani, A. T., \& Kiswoyo, K. (2019). Keefektifan Model Pembelajaran Number Head Together (NHT) Berbantu Media Puzzle Terhadap Hasil Belajar Matematika. Jurnal Ilmiah Sekolah Dasar, 3(2), 192. https://doi.org/10.23887/jisd.v3i2.17772.

Kurniaman, \& Wuryandani. (2017). Pengaruh Model Pembelajaran Berbasis Masalah terhadap Motivasi Belajar dan Hasil Belajar PPKn. Jurnal Civics, 14(1). https://doi.org/https://doi.org/10.21831/civics.v14i1.14558.

Kurniawan, D., \& Saragih, A. H. (2016). Pengembangan Bahan Pembelajaran Media Interaktif Pada Mata Pelajaran Ppkn. Jurnal Teknologi Informasi \& Komunikasi Dalam Pendidikan, 3(1), 1-13. https://doi.org/10.24114/jtikp.v3i1.5001.

Kurniawan, M. W., \& Wuryandani, W. (2017). Pengaruh model pembelajaran berbasis masalah terhadap motivasi belajar dan hasil belajar PPKn. Jurnal Civics: Media Kajian Kewarganegaraan, 14(1), $10-$ 22. https://doi.org/10.21831/civics.v14i1.14558.

Lestari, K. P., Putra, D. K. N. S., \& Negara, I. G. A. O. (2018). Pengaruh Model Discovery Learning Berbantuan Media Audio Visual dalam Setting Lesson Study Terhadap Hasil Belajar IPA Mahasiswa PGSD Undiksha UPP Denpasar Tahun 2017. Jurnal Ilmiah Sekolah Dasar, 2(1), 40-45. https://doi.org/http://dx.doi.org/10.23887/jisd.v2i1.13898.

Marwiyati, S., \& Istiningsih, I. (2021). Pembelajaran Saintifik pada Anak Usia Dini dalam Pengembangan Kreativitas di Taman Kanak-Kanak. Jurnal Obsesi: Jurnal Pendidikan Anak Usia Dini, 5(1). https://doi.org/https://doi.org/10.31004/obsesi.v5i1.508.

Masturah, E D, Mahadewi, L. P. P., \& Simamora. (2018). Pengembangan Media Pembelajaran Pop-Up Book pada Mata Pelajaran IPA Kelas III Sekolah Dasar. Jurnal EDUTECH ..., 6(2), 212-221. https://doi.org/http://dx.doi.org/10.23887/jeu.v6i2.20294.

Masturah, Elisa Diah, Mahadewi, L. P. P., \& Simamora, A. H. (2018). Pengembangan Media Pembelajaran Pop-Up Book pada Mata Pelajaran IPA Kelas III Sekolah Dasar. Jurnal EDUTECH Universitas Pendidikan Ganesha, 6(2), 212-221. https://doi.org/http://dx.doi.org/10.23887/jeu.v6i2.20294. 
Maulidati, I. S., Dantes, N., \& Tika, N. (2019). Pengaruh Pembelajaran Berpendekatan Saintifik Berorientasi Science Environment Technology Society Terhadap Kemampuan Berpikir Kritis Dan Hasil Belajar Ipa Siswa Kelas V. PENDASI: Jurnal Pendidikan Dasar Indonesia, 2(2), 59-71. https: //doi.org/10.23887/jpdi.v2i2.2693.

Mediatati, N., \& Suryaningsih, I. (2017). Penggunaan Model Pembelajaran Course Review Horay Dengan Media Flipchart Sebagai Upaya Meningkatkan Hasil Belajar PKn. Jurnal Ilmiah Sekolah Dasar, 1(2). https://doi.org/http://dx.doi.org/10.23887/jisd.v1i2.10146.

Meilani, D., Dantes, N., \& Tika, I. N. (2020). Pengaruh Implementasi Pembelajaran Saintifik Berbasis Keterampilan Belajar dan Berinovasi 4C terhadap Hasil Belajar IPA dengan Kovariabel Sikap Ilmiah pada Peserta Didik Kelas V SD Gugus 15 Kecamatan Buleleng. Jurnal Elementary: Kajian Teori Dan Hasil Penelitian Pendidikan Sekolah Dasar, 3(1), 1-5. https://doi.org/https://doi.org/10.31764/elementary.v3i1.1412.

Mustika, D., \& Ain, S. Q. (2020). Peningkatan Kreativitas Mahasiswa Menggunakan Model Project Based Learning dalam Pembuatan Media IPA Berbentuk Pop Up Book. Jurnal Basicedu, 4(4), 1167-1175. https://doi.org/https://doi.org/10.31004/basicedu.v4i4.518.

Mustofa, R., \& Syafi'ah, R. (2018). Pengembangan Media Pembelajaran Pop Up Book Materi Kenampakan Permukaan Bumi Mata Pelajaran IPA Kelas III SD. ELSE (Elementary School Education Journal), 2, 30-41. https://doi.org/http://dx.doi.org/10.30651/else.v2i2.1723.

Nikmah, S., Nuroso, H., \& Reffiane, F. (2019). Pengaruh Model Pembelajaran Terpadu Tipe Shared Berbantu Media Pop- Up Book Terhadap Hasil Belajar. Jurnal Pedagogi Dan Pembelajaran, 2(2), 264. https://doi.org/10.23887/jp2.v2i2.17920.

Ningtiyas, T., Setyosari, P., \& Praherdiono, H. (2019). Pengembangan Media Pop-Up Book Untuk Mata Pelajaran Ipa Bab Siklus Air Dan Peristiwa Alam Sebagai Penguatan Kognitif Siswa. Jurnal Kajian Teknologi Pendidikan, 2(2), 115-120. https://doi.org/10.17977/um038v2i22019p115.

Oktarina, N. D., \& Liyanovitasari, L. (2019). Media Cerita Bergambar Tentang Pengenalan Seks Dini Meningkatkan Pengetahuan Anak Usia Dini. Jurnal Kesehatan Perintis (Perintis's Health Journal), 6(2), 110-115. https://doi.org/https://doi.org/10.33653/jkp.v6i2.296.

Palunga, \& Marzuki. (2017). Peran Guru Dalam Pengembangan Karakter Peserta Didik Di Sekolah Menengah Pertama Negeri 2 Depok Sleman. Jurnal Pendidikan Karakter, 1(1). https://doi.org/https://doi.org/10.21831/jpk.v7i1.20858.

Primasari, R. (2014). Penggunaan Media Pembelajaran di Madrasa Aliyah Negeri Se-Jakarta Selatan. Edusains, 6(1), 68-72. https://doi.org/https://doi.org/10.15408/es.v6i1.1101.

Putri, A. D. (2019). Perancangan Media Pembelajaran Interaktif Berbasis Android Pada Mata Pelajaran Ilmu Pengetahuan Sosial Untuk Anak Sekolah Dasar. Jurnal Hasil Penelitian Dan Industri Terapan, 8, 57-68. https://doi.org/https://doi.org/10.31629/sustainable.v8i2.1575.

Qondias, D., Winarta, \& Siswanto. (2019). Pengembangan Bahan Ajar Berbasis Pendekatan Saintifik pada Mata Kuliah Metodologi Penelitian. Jurnal Penelitian Dan Pengembangan Pendidikan, 3(2), 145148. https://doi.org/doi.org/10.23887/jppp.v3i2.17393.

Rusmiati, R., \& Nugroho, A. S. (2019). Pengaruh Model Pembelajaran TGT dengan Media Pop Up Terhadap Hasil Belajar Kelas IV Tema 6 Cita-Citaku Subtema 3. Jurnal Pedagogi Dan Pembelajaran, 2(2), 241. https://doi.org/10.23887/jp2.v2i2.17914.

Salim, A. (2016). Pendekatan Saintifik Dalam Pembelajaran Pendidikan Agama Islam (Pai) Di Madrasah. Cendekia: Jurnal Kependidikan Dan Kemasyarakatan, 12(1). https://doi.org/https://doi.org/10.21154/cendekia.v12i1.362.

Sari, A. S., \& Azzah, U. (2017). The Development of Pop-up Book on the Role of Buffer in the Living Body. European Journal of Social Sciences Education and Research, 4(4), 213-221. Retrieved from http://journals.euser.org/index.php/ejser/article/view/2430.

Sentarik, K., \& Kusmariyatni, N. (2020). Media Pop-Up Book pada Topik Sistem Tata Surya Kelas VI Sekolah Dasar. Jurnal Ilmiah Sekolah Dasar, 4(2), 197. https://doi.org/10.23887/jisd.v4i2.25135

Solehana, L., Asrori, A., \& Usman, A. (2019). The Development of E-Learning Teaching Material Based on Edmodo on Basic Competencies of National Integration at Class X of Senior High School. Journal Of Education, Teaching And Learning, 4(2). https://doi.org/https://doi.org/10.26737/jetl.v4i2.1914.

Sophuan, S. (2018). Peningkatkan Keterampilan Mengajar Guru Smp Mata Pelajaran Ipa Dalam Menerapkan Pendekatan Saintifik. Tadrib: Jurnal Pendidikan Agama Islam, 4(2). https://doi.org/https://doi.org/10.19109/tadrib.v4i2.2860.

Sriyanto, Leksono, \& Harwanto. (2019). Bahan Ajar PPKn Berbasis Karakter dan Literasi Untuk Siswa Kelas IX SMP Al Hikmah Surabaya. Edmotech, 4(2), 130-142. https://doi.org/http://dx.doi.org/10.17977/um039v4i22019p130. 
Suartama, I. K. (2016). Evaluasi dan Kriteria Kualitas Multimedia Pembelajaran. Singaraja: Universitas Pendidikan Ganesha.

Sugiyono. (2015). Metode Penelitian Pendidikan. Bandung: Alfabeta.

Suprihatin. (2017). Penggunaan Media Pengajaran Untuk Meningkatkan Prestasi Belajar Mata Pelajaran PPKn Pada Siswa Kelas X Semester I Smk Negeri 1 Bendo Kecamatan Bendo Kabupaten Magetan Tahun Ajaran 2014/2015. Citizenship: Jurnal Pendidikan Pancasila Dan Kewarganegaraan, 3(2). https://doi.org/http://doi.org/10.25273/citizenship.v3i2.1259.

Suwatra, Magta, \& Christiani. (2019). Pengaruh Media Busy Book Terhadap Kemampuan Problem Solving Anak Kelompok A Taman Kanak-Kanak. Mimbar Ilmu Undiksha, 24(2), 185-193. https://doi.org/http://dx.doi.org/10.23887/mi.v24i2.21257.

Tegeh, I. M., Jampel, I. N., \& Pudjawan, K. (2014). Model Penelitian Pengembangan. Singaraja: Universitas Pendidikan Ganesha..

Vista, Hermita, \& Zufriady. (2019). Penerapan Model Pembelajaran Kooperatif Tipe Talking Stick Berbantuan Media Question Box untuk Meningkatkan Hasil Belajar IPS Siswa Kelas III SDN 161 Pekanbaru. Jurnal Tunjuk Ajar, 20-29. https://doi.org/http://dx.doi.org/10.31258/jta.v2i1.20-29.

Widnyani, Dantes, \& Tegeh. (2015). Pengaruh Pendekatan Saintifik Terhadap SikapSpiritual Siswa dengan Kovariabel Intensitas Hubungan Dalam Pola Asuh Keluarga. Mimbar PGSD Undiksha, 3(1). https://doi.org/http://dx.doi.org/10.23887/jjpgsd.v3i1.5635.

Wulandari, Sudatha, \& Simamora. (2020). Pengembangan Pembelajaran Blended Pada Mata Kuliah Ahara Yoga Semester II di IHDN Denpasar. Jurnal Edutech Undiksha, 8(1), 1-15. https://doi.org/http://dx.doi.org/10.23887/jeu.v8i1.26459.

Yendrita, \& Syafitri. (2019). Pengaruh Penggunaan Media Video Pembelajaran Terhadap Hasil Belajar Biologi. Jurnal Pendidikan Biologi Dan Sains, https://doi.org/https://doi.org/10.31539/bioedusains. v2i1.620.

Yuanta, F. (2019). Pengembangan Media Video Pembelajaran Ilmu Pengetahuan Sosial pada Siswa Sekolah Dasar. Jurnal Pendidikan Dasar, 1(2). https://doi.org/http://dx.doi.org/10.30742/tpd.v1i02.816. 